\title{
REAÇÕES E SENTIMENTOS DO PROFISSIONAL DE ENFERMAGEM DIANTE DA MORTE
}

\author{
FEELINGS AND REACTION OF NURSES IN FACE OF DEATH \\ REACCIONES Y SENTIMIENTOS DEL PROFESIONAL DE ENFERMERIA \\ DELANTE DE LA MUERTE
}

\author{
Edna Lúcia Martins ${ }^{\prime}$ \\ Rozilda das Neves Alves ${ }^{2}$ \\ Sueli Aparecida Ferreira de Godoy ${ }^{3}$
}

\begin{abstract}
RESUMO: Através deste estudo, do tipo exploratório descritivo, propomos compreender as reações e sentimentos dos profissionais de enfermagem diante dos pacientes fora de possibilidade terapêutica. Foram realizadas entrevistas individuais, semi-dirigidas, com nove profissionais de enfermagem ( 6 aux. de enfermagem e 3 enfermeiras) de um hospital geral da cidade de MaringáPR. Constatamos que, para estes profissionais, o fato de lidarem com a morte diariamente é extremamente angustiante e, portanto, utilizam de mecanismos de defesa tais como negação, racionalização, para conviverem com as perdas rotineiras. Isto faz com que os profissionais de enfermagem podem deixar de perceber as limitaçöes e angústias do paciente, o que pode vir a comprometer a qualidade do trabalho assistencial. Com base nos resultados encontrados, sugerimos a criação de um espaço terapêutico no hospital, com os profissionais da saúde, para que através de grupos de reflexāo a expressāo das angústias, medos, impotência e dor diante da morte e do morrer possa ser facilitada e compartilhada.
\end{abstract}

PALAVRAS-CHAVE: enfermagem, hospital, morte, paciente fora de possibilidade terapẽutica.

\section{INTRODUÇÃO}

Uma das grandes dificuldades dos profissionais de saúde que prestam atendimento a pacientes fora de possibilidade terapêutica, é não reconhecer a própria finitude. Utilizam-se de mecanismos de defesa para negar um acontecimento natural e inevitável da vida, ou seja, a morte.

O discurso institucional, em nome do profissionalismo, estimula a impessoalidade e tenta distanciar quem trabalha no hospital dos principais fatos que configuram esta realidade, isto é, a dor, o sofrimento e a morte. Assim, nos apercebendo da nossa condição humana, vemos que a dor e o sofrimento não são simplesmente sintomas e a morte somente óbito mas, sentimentos e acontecimentos que nos afetam e angustiam

Menzies(1970,p.13) aponta que a luta contra a ansiedade leva, em instituições, ao "desenvolvimento de mecanismos de defesa estruturados socialmente que aparecem como elementos na estrutura, na cultura e no modo de funcionamento da organização".

Em nossa prática como psicólogos que atuam em hospitais gerais temos observado que a equipe de enfermagem, não raras vezes apresenta dificuldades profissionais e pessoais

\footnotetext{
'Acadêmica do $5{ }^{\circ}$ ano do curso de Psicologia da Universidade Estadual de Maringá (UEM).

2 Professora Assistente do Curso de Psicologia da UEM, Mestre em Psicologia Social.

${ }^{3}$ Psicóloga do Instituto de Infectologia Emilio Ribas, SP.
} 
que acabam por interferir na dinâmica e na assistência prestada, por estes, aos pacientes. Essas dificuldades dizem respeito às angústias relacionadas, entre outras, à possibilidade de morte do paciente; aos sentimentos de impotência e, a desvalorização do seu trabalho por parte de alguns membros da equipe multiprofissional.

De acordo com o exposto, acreditamos que o psicólogo, que irá intervir junto à enfermagem em hospitais, necessita conhecer o funcionamento dessa equipe, suas dificuldades em lidar com as questōes emocionais frente a morte, perda da função corporal, perda de um membro do corpo, as ansiedades despertadas diante do trabalho, o stress, a desvalorização profissional.

Assim, como forma de repensar a atuação do profissional de enfermagem de maneira que favoreça as relações deste com os pacientes fora de possibilidade terapêutica sentimos a necessidade de investigar as reaçōes e sentimentos dos membros da equipe de enfermagem quando prestam atendimento a esses e quais as consequeências, ou seja, quais as implicaçōes que se explicitam neste atendimento.

Julgamos que esse conhecimento favorecerá a otimizaçăo das ações do psicólogo no hospital, que poderá intervir junto à equipe de enfermagem, utilizando-se de técnicas adequadas ao contexto hospitalar, com o intuito de que estes possam vivenciar as perdas no dia a dia de seu trabalho de uma forma mais saudável, o que acreditamos, implicaria na melhoria da qualidade do atendimento prestado por este ao paciente fora de possibilidade terapêutica.

Esperamos, ainda, que as intervençōes junto à equipe de enfermagem reverta também em beneficio para o paciente hospitalizado pois, a elaboração da morte por parte do profissional possibilitaria a este propiciar ao paciente, morrer com dignidade.

\section{O HOSPITAL E A MORTE}

A relaçăo do ser humano com a morte vem se transformando no decorrer do tempo. Segundo Maranhäo(1992), nos últimos cinqüenta anos houve uma ruptura histórica na maneira como as pessoas vivenciam a morte. Esta se tornou vergonhosa, ou seja, antes ela era reconhecida e vivenciada, hoje è encoberta e disfarçada, se tornou objeto de interdição:

"...o que era conhecido é dissimulado. O ideal é que [ se] morra sem se dar conta de sua morte, que jamais [se] saiba que seu fim se aproxima" (Maranhão, 1992,p.12). Essa mudança de atitude deve-se ao deslocamento do lugar da morte para o hospital. Isto ocorreu, em parte, devido ao avanço tecnológico da medicina e da cirurgia (Maranhão, 1992, p.12).

Guedes; Torres (1984) apontam algumas falácias sobre a hospitalização e os aspectos que a rodeiam (doença, morte, cura) que interferem no desenvolvimento pessoal e profissional dos individuos que atuam em hospitais. Entre elas eståo:

- a concepção de que o hospital é um lugar exclusivamente de cura;

-"... mesmo quando a morte è inevitável ninguém deseja morrer" (p.104);

- O paciente näo quer saber de sua morte;

- "As emoçōes interferem na objetividade (...) do médico.." (p.106);

- Há uma impossibilidade de aceitação e preparação para a morte e,

- os "... aspectos (...) nāo técnicos não são importantes para a cura" (p.106).

Podemos perceber que apesar do hospital ter se transformado no lugar onde a morte acontece, os sentimentos e os acontecimentos envolvidos no morrer não foram transportados para lá. Relembrando o que escreveu Cassorla $(1991, p .21)$ "o problema do luto mal-elaborado é grave, porque (...) alastra-se por geraçōes, filhos identificando-se com pais melancólicos e passando esta mesma melancolia para seus filhos". Assim, por analogia podemos refletir que, se o luto não pode também ser elaborado no hospital, as pessoas que lá trabalham vivem num ambiente melancólico que acaba por refletir na esfera social. 


\section{A EQUIPE DE ENFERMAGEM DIANTE DA MORTE}

Fernandes, Fujimori e Koizume (1984,p.102) referem que "a assistência de enfermagem tem como finalidade atender as necessidades básicas do ser humano nos seus aspectos biopsicossocio-espirituais" , considerando o paciente como ser integral e, nessa assistência inclui-se proporcionar ao individuo uma morte tranquila. No entanto, como apontado anteriormente, no hospital a morte tende a ser negada, ou seja, a morte não é vista como um acontecimento natural, e sim como um acontecimento que causa frustração, sensação de fragilidade e de incapacidade. Estes sentimentos se tornam exacerbados quando o papel do enfermeiro é confrontado com o ajudar a morrer com dignidade pois, o profissional de enfermagem é instruido para salvar vidas (Rockenbach,1985).

Ferraz et al. (1986) também mostraram que enfrentar a morte, os sentimento de impotência, o receio de transmitir seus medos e angústias ao paciente e sentimento de mal-estar e dificuldade porque se envolveu emocionalmente são algumas dificuldades sentidas pelo profissional de enfermagem em seu trabalho.

Boemer, Rossi e Nastari (1989) colocam que, na U.T.I., o problema da reflexão da morte é mais dificil, pois sua própria dinâmica năo possibilita momentos para essa reflexão.

Spindola e Macedo (1994,p. 109) relatam, em sua pesquisa com profissionais que atuam em C.T.I., que "o contato com o morrer era constante e sempre, nestes momentos, ficava com uma sensação de vạzio, de fracasso". Estes autores perceberam, ainda, que os profissionais, ao assistirem o morrer do paciente, mostravam, entre outras reações, uma sensação de frustração, tristeza e perda e que a forma como a morte do paciente era vivenciada dependia da idade, do diagnóstico e do prognóstico do paciente.

Torres et al.(1989,p.67) em sua pesquisa sobre atitudes frente a morte, mostram que o grupo de enfermagem devido a grande diferença entre a alta responsabilidade no que se refere aos cuidados do corpo "... e o baixo poder de decisão quanto às condutas de intervenção e a adoção de procedimentos técnicos para com esse corpo", é um dos grupos que expressa maior inquietação e se mostra mais defensivo frente aos aspectos da morte e do morrer. Neste sentido, Menzies(1970,p.11) afirma que "pela própria natureza de sua profissão, a enfermeira corre um considerável risco de ser invadida por uma ansiedade imensa e incontrolável". Por isto, muitas vezes os profissionais de enfermagem apresentam um distanciamento emocional no atendimento prestado, quando verificam a eminência de morte no paciente. No entanto, Fernandes, Fujimorie Koizume(1984)e Cheida e Christófolli(1984), apontam que é o sentimento de onipotência, relacionado ao fato de que a profissão busca basicamente a cura do outro, afastando a possibilidade de morte, que faz com que atribuam grande valor ao atendimento técnico, diminuindo a relação interpessoal.

Rockenbach $(1985, p .54)$ considera necessário um aperfeiçoamento da equipe de enfermagem não apenas no que tange as questões técnicas, mas, principalmente no que diz respeito ao desenvolvimento como ser humano, e pondera que as escolas e as instituiçőes hospitalares deveriam se ater mais a estas questöes "... nos seus programas de formação permanente e vivências terapêuticas de personalidade".

Torres et al. $(1989, p .70)$ destacam a importância de uma reformulação dos curriculos dos cursos de enfermagem "visando inserir um treinamento nas áreas de dor, da perda e da morte". Isto é necessário para que uma mudança em nivel de comportamento frente a morte possa ocorrer, conduzindo a uma mudança nas atitudes para com os pacientes fora de possibilidade terapêutica (Torres et al., 1989).

No entanto, a assistência emocional ao paciente não está comprometida somente pela falta de preparo na formação escolar, mas também como coloca Ferreira(1992) "... pela sobrecarga de trabalho, paciente dificil e dificuldades no relacionamento entre equipes".

Cheida e Christófolli(1984,p. 171) consideram de grande importância a atuação do psicólogo 
juntamente aos pacientes fora de possibilidade terapêutica e a equipe de saúde e a necessidade "de um treinamento desta equipe em técnicas de abordagem". Estas autoras frisam, ainda, a relevância do auxilio ao paciente fora de possibilidade terapêutica, para que este tenha possibilidade de alcançar a fase da "aceitação".

\section{METODOLOGIA}

Trata-se de estudo do tipo exploratório descritivo, no qual a análise de conteúdo foi o mètodo usado para a compreensão dos discursos. Foi feito um recorte das entrevistas para que pudéssemos melhor explorar a problemática das reaçöes e sentimentos dos profissionais frente a morte. Recorte, este, composto de três temas: 1 - reações frente a morte do paciente; 2 interação com o paciente fora de possibilidade terapêutica e, 3- dificuldades diante da morte.

Foram realizadas entrevistas individuais, semi-dirigidas, com nove profissionais de enfermagem de um hospital geral da cidade de Maringá - PR, no local de trabalho dos entrevistados. Foi considerado como pré-requisito para a participação na pesquisa que todos os profissionais tivessem atendido pacientes fora de possibilidade terapêutica ${ }^{4}$ no decorrer do exercicio profissional.

Para as entrevistas foi utilizado um roteiro com tópicos sobre a relaçăo com o paciente e vivência acerca da morte.

As entrevistas, com duração média de 20 minutos, foram gravadas e realizadas durante os meses de setembro e outubro de 1996, sempre respeitando a disponibilidade dos profissionais e a dinâmica da unidade ou setor.

Os profissionais foram consultados sobre o consentimento para participação na pesquisa e thes foi assegurado o sigilo de identidade. Durante o primeiro contato foram explicitados os objetivos da pesquisa, assim como, foi-lhes garantido que nenhum material que os identificasse seria disponibilizado para as chefias do hospital.

\section{APRESENTAÇĀO E DISCUSSĀO DOS RESULTADOS}

\section{CARACTERISTICAS DA AMOSTRA}

Dos 9 entrevistados, $8(89 \%)$ eram do sexo feminino e $1(11 \%)$ do sexo masculino. Seis (6) eram auxiliares de enfermagem (66,7\%), incluindo o único homem da amostra e $3(33,3 \%)$ enfermeiras. A idade média foi de 27 anos, sendo a menor 19 anos e a maior 35 anos. Quanto ao setor de trabalho, $2(22 \%)$ atendiam na U.T.I. (Unidade de Terapia Intensiva), $2(22 \%)$ na Infectologia e $5(56 \%)$ na Ala Clínica Geral.

\section{REAÇÕES FRENTE AMORTE DO PACIENTE}

Entre os nove entrevistados, quando perguntados sobre a sua reação frente a morte de um paciente, apenas um referiu como reação "năo comentar nada com ninguém". Os

- O termo paciente fora de possibilidade terapêutica, neste trabalho, será empregado no mesmo sentido de paciente terminal descrito por Piva e Carvalho (1993, p.130): "determinado momento na evoluçăo de uma doença que, mesmo que se disponha de todos os recursos, o paciente não é mais salvável, ou seja, está em processo de morte inevitável. Este conceito não abrange apenas a potencialidade de cura ou reversibilidade de uma função orgânica atingida[...]. Refere-se áquele momento em que as medidas terapêuticas, neste caso, torna-se fủtil ou pressupōe sofrimento" 
outros relataram diferentes reações e entre elas estăo: comentar com alguém (da própria equipe); preparar o morto; confortar a familia; cuidar de outros pacientes; tentar esquecer e disfarçar; aceitação (quando o prognóstico era ruim); se comparar com o paciente e, chorar (fora do hospital).

Quando $85.7 \%$ dos sujeitos referem que comentam sobre a morte, no setor, com o "pessoal da área" consideramos que esta pode ser uma maneira de procurar compartilhar com pessoas que sabidamente thes dizem o que querem ouvir, ou seja, pessoas que vêem o acontecimento da mesma forma, com as mesmas resistências. Por outro lado, comentar com pessoas de fora implicaria em vivenciar sentimentos que năo se quer sentir como, por exemplo, sentimento de perda ou, ainda, como refere Rita ${ }^{5}$ : "não leva para fora [do hospital] para näo atrapalhar no dia a dia", pois a morte é tema interditado, banido das nossas comunicaçōes rotineiras justamente porque mobiliza muita angústia.

Assim, a morte de um paciente é percebida pelo grupo de enfermagem como algo que tem que ser controlado para não deixar desorientar [pois] se você também se desorienta, não tem como (...) (Ana). Como referido por Alves e Godoy(1997) o discurso institucional estimula a impessoalidade e frieza na relação com o paciente como construção do bom desempenho profissional.

Ana nos fala que às vezes é preciso confortar a familia. Podemos inferir que confortar a familia significa, confortar a si mesmo pois, permitir que a familia se desoriente, no momento em que recebe a noticia de morte de um familiar, é permitir se desorientar também e com isso aceitar e reconhecer que perdeu um paciente no qual se investiu muito. Sendo assim, o menos angustiante parece ser disfarçar e esquecer: Não [se pode] passar por isso, temos mais pacientes pra cuidar, outros problemas para resolver" (Ana). Disfarçar e esquecer evidenciam o mecanismo de negaçăo.

A solidariedade para com a familia proporciona uma maneira de vivenciar a tristeza e a perda do paciente, através do mecanismo de identificação:

Eu procuro ficar bem próximo da familia, porque eles acabam te comovendo, te sensibilizando cada vez mais. Ai entra um pouco da sua personalidade (...) Eu acabo sofrendo junto com a familia porque ver uma mảe, pai ou qualquer pessoa que esteja chorando aqui dentro, isso dói demais, tira as suas forças de lidar com o doente (Vinicius).

Acabei chorando junto com o pai! O desespero dele foi tão grande e ele estava tão triste e eu acabei chorando junto com ele (Malu).

Nesses momentos chorar com o familiar é, também, chorar por outras perdas acontecidas ao longo da vida, que a morte atualiza, torna presente.

Percebemos que uma das causas da intensa angústia vivida pelos profissionais diz respeito ao conflito entre o papel profissional a ser desempenhado e a morte (uma das realidades do hospital):

... a gente faz, faz pelo paciente e chega no final vai tudo embora e a gente estudou não foi para isso! (Rita).

Constatamos, também, que existe uma "cultura", no meio hospitalar, de que o bom profissional de enfermagem năo deve se envolver. No entanto, os relatos de nossos entrevistados nos mostram o intenso conflito vivido por eles e que certos estereótipos acerca da profissão săo falsos:

O pessoal diz que a enfermagem é fria. Não! Há companheiras que entram também em desespero, têm que ser tiradas rapidinho e escondidas (Ana).

\footnotetext{
${ }^{5}$ A identificação dos sujeitos entrevistados foi feita através de nomes ficticios com o intuito de preservarmos a identidade dos mesmos.
} 
...não tem como você dizer que a gente é fria, calculista, essa é uma mentira enorme, a gente tenta ... suprir ... passar por cima disto, porque se você deixar cair, você não tem estrutura nenhuma para trabalhar num local deste (Maria).

Vemos assim que a realidade hospitalar parece não comportar a vivência destes profissionais que, não encontrando espaço para a expressão de sua dor e angústia, se defendem: racionalizando, negando, distanciando e encobrindo seus sentimentos pois, a expressăo dos mesmos desqualifica o desempenho profissional

O prognóstico ruim parece "preparar" o profissional para a morte de seu paciente, entretanto, a "morte súbita" ou de pacientes jovens acentuam os sentimentos de impotência, identificação e culpa:

Alguns eu sinto que poderia ter feito mais alguma coisa (Rita).

Quando é um paciente que (...) o estado dele é ruim (...) eu encaro com mais facilidade (...). Agora, morte súbita é uma coisa mais dificil, a gente acha que poderia ter feito mais alguma coisa (...) mas, não me abalo a ponto de impedir de realizar outras tarefas (Malu).

tinha um paciente com problema de pulmão ele faleceu no nosso horário ... e eu tinha asma (...) que agonia! Eu estava me vendo naquele homem porque eu também tive crise ... Depois ver ele morrer da mesma coisa! (Mariana).

Eu lembro que era um paciente novo... de repente teve uma parada... o médico tava no setor, correu, pegou isso, pegou aquilo, estressou todo mundo para tentar salvare não conseguiu nada (Ana).

Teve alguns pacientes jovens ai sim! ... que a gente segura eles ... que emocionalmente a gente ficou muito abalada (...) vocẻ começa a comparar! Então você se coloca muito no lugar (...) [ a gente tem que ] tentar se apegar em um outro paciente e tentar ver outra coisa ... ou achar uma desculpa pela morte do paciente (...) porque às vezes você acha que é impotência sua (...) puxa! (Maria).

Este relatos indicam que é dificil lidar com a morte súbita de um paciente. A morte súbita traz insegurança para muitos, pois, é uma morte que acontece de repente e, se aconteceu com o paciente pode acontecer com qualquer um, inclusive com o próprio profissional. Este reconhecimento implica num distanciamento do profissional desse paciente, porque é muito angustiante estar próximo de algo que pode acontecer consigo mesmo. Na morte súbita há uma identificação do profissional com o paciente. A angústia se intensifica e o sofrimento também, mobilizando grandes quantidades de energia para evitar reconhecer e vivenciar esta situação geradora de angústia.

Temos, assim, que as reações dos profissionais apesar de comportar uma expressăo singular é delimitada pelo espaço de trabalho e pelos estereótipos da profissão. As falas seguintes nos mostram que os profissionais de enfermagem vivem uma grande contradição: a morte tem que ser esquecida no lugar em que a sociedade elegeu para que ela ocorra. A fala de Ana é uma sintese desta contradição:

...às vezes a gente tem que parar um pouquinho pra ... não digo para chorar... às vezes dá vontade de chorar. Quando a gente entra dá um pouquinho de angústia, mas a gente não pode passar para eles (...) näo podemos passar por isso ... temos mais pacientes pra cuidar. outros problemas pra resolver. A gente tenta esquecer e disfarçar do mesmo jeito que a familia tem que esquecer (Ana).

Rosa nos coloca que no hospital é diferente porque são várias pessoas que morrem, então não marca muito. Percebemos que quanto mais mortes ocorrem, mais comum a morte parece ser, podendo ocorrer uma banalização da morte nos hospitais. No entanto, talvez seja um comum camuflado pela negaçăo pois, se considerarmos as mortes "comuns" significa que estaremos aceitando-a como uma fase do ciclo vital (do desenvolvimento humano), e se reconhecermos a morte no outro, obviamente, estaremos reconhecendo-a em nós mesmos. Tenta-se fazer, assim, deste lugar "comum", um lugar que não seja tão amedrontador. 
Tornar o objeto que dá medo, que "ameaça o sentido de ordem (...) e a sensação de controle do mundo" (Joffe1995, p.297), em algo com uma "feição familiar", è uma forma de lidar com o desconhecido.

Muitas vezes confunde-se a negação e banalizaçăo da morte com a elaboração e aceitação. A negação e banalização, não oferecem senão uma solução passageira para a questão da morte, o que muitas vezes é preciso para o profissional continuar exercendo suas funções sem sucumbir. Mas coloca a equipe em um estado de stress permanente, pois as defesas podem falhar e a angústia permanece sem via de expressão. Enquanto que a elaboração e a aceitação fazem parte de um processo de desenvolvimento pessoal, que reflete no desenvolvimento profissional.

Por outro lado, reconhecer o morrer do outro, pode significar um alivio pois, é o outro quem está morrendo e "isto não vai acontecer comigo!". Esse reconhecimento pode levar a um sentimento de compaixão para com o paciente. Este sentimento pode contaminar a relação com o mesmo e, por vezes impedir o profissional de perceber as reais necessidades do doente e assim deixar de contribuir para uma morte mais digna.

Em relação ao sentimento de perda e a vivência da tristeza no hospital, alguns profissionais deixam transparecer em suas falas o fato de não poderem vivenciar essas tristezas, para que consigam trabalhar num ambiente como o hospital (Ana e Maria), deixando claro, assim, o isolamento total ou parcial desses sentimentos. Como coloca Dewald ${ }^{[5]}$, isolar consiste no fato de que as manifestações psiquicas estão separadas nas partes que as compõem e a união entre estas partes e o conhecimento consciente está bloqueada, impedindo a vivência desses sentimentos.

\section{A INTERAÇÃO COM O PACIENTE FORA DE POSSIBILIDADE TERAPÊUTICA}

Verificamos que a maneira como o profissional de enfermagem interage com o paciente fora de possibilidade terapêutica e demais pacientes são diferentes, apesar dos entrevistados alegarem que esta diferença não ocorria:

.... Não é que é diferente, só que ${ }^{6} \mathrm{com}$ o paciente que está em fase terminal eu procuro conversar mais ... procuro achar um tempinho a mais. Com os outros não, a gente já vai, faz o serviço ... às vezes eles chamam para conversar, a gente conversa. Agora os que estão em fase terminal a gente procura agradar mais, dar um carinho a mais (Carla). forma (Malu).

Eu tento tratar os pacientes da mesma forma (...) eu procuro tratar todos da mesma

Aqui dentro é quase a mesma coisa (Vinicius).

Observamos que a relação com outros pacientes é mais amena, mais fácil e, em geral, è boa: É muito boa, inclusive a gente brinca, porque o nosso setor é sempre cheio, então ... vive dando risada, brincando (Mariana). No entanto, quando o relacionamento é estabelecido com o paciente fora de possibilidade terapêutica, encontramos diferentes formas de comportarse: dependendo do paciente se aproximam ou se afastam; não dizem

nada e só agem; se dedicam mais ao paciente; ficam impotentes ou falam com franqueza sobre a morte.

\section{Aproximação/Afastamento}

Tem paciente que eu fico muito perto deles mas, tem outros que ... a gente näo se dava (...) eu já tive problemas (...) de pedir as coisas e năo colaborar (Rita).

\footnotetext{
${ }^{6}$ Grifo nosso.
} 
Depende do paciente, eu me afasto. Depende muito do paciente. Tem pacientes que eu tenho uma rejeição enorme, pacientes de hemodiálise (...) eu tenho bloqueio muito grande. Com idosos em fase terminal eu tenho o maior carinho (Maria).

\section{Silêncio/Açāo}

Eu procuro fazer as coisas para ele, do que eu dizer (...) muitas vezes o gesto fala mais alto do que as próprias palavras (Vinicius).

\section{Dedicaçăo}

Eu acho. Eu sinto que me dedico mais para eles, do que um outro paciente ... não sei se é pelo fato deles já estarem na fase terminal, a gente procura agradar mais (Carla).

Tem que mostrar segura do que você tá fazendo. Em primeiro lugar procurar confortaro paciente, tirar suas angústias, seus medos, eles têm muito medo, insegurança. Eles tão muito carentes, passar esse carinho para eles, que você tá atenta, está olhando, então é por isso que você se apega. Como eles estão muito sensibilizados, a mercê de tudo ... eles acabam te pegando, te adotando, se agarrando em você, e você tem que fazer o melhor possivel passando conforto, segurança e tranqüilidade para o paciente (Ana).

A gente fica tentando fazer alguma coisa, mas ao mesmo tempo que tá tentando fazer ... vocẻ sabe que nảo tem condiçōes... dá uma coisa ruim, porque você vai fazer um monte de coisa que você sabe que não vai adiantar(Mariana).

\section{Impotência:}

Dó, dó né! ... Vocể vê a pessoa chegar bem, ... aí cada dia que passa você vê que ela tá piorando, que ela vai indo ... Sei lá! ... a gente vê que o paciente tá indo embora (...) a gente sabe o que vai acontecer, e o que vai fazer? (Rosa).

\section{Franqueza}

Eu procuro não esconder a verdade do paciente. Às vezes o médico chega até mentir dizendo que não! ... que ele vai viver mais algum tempo. Agora eu não! Eu chego e falo para o paciente que vai morrer e pronto (Joana).

A maneira como o profissional de enfermagem interage com o paciente fora de possibilidade terapêutica, ganha colorido diverso porém, vem ilustrar-nos a dificuldade da equipe de enfermagem em lidar com um momento da vida que se tornou um tabu na sociedade ocidental, que suscita dores profundas na alma. É uma relação de ajuda que suscita a impotência destes profissionais, ainda mais quando há o peso depositado pela familia e às vezes pelo próprio paciente para que continuem vivos, isto é, que eles (equipe de enfermagem) não os deixem morrer.

Kovács (1992, p.3)relata que a representaçăo da morte como "ausência, perda, separação, e a conseqüente vivência de aniquilação e desamparo" está relacionada com as mais remotas experiências de ausência materna vivida pela criança. Estas ausências, vivenciadas como solidão e desamparo, ficarão para sempre marcadas. Esta autora, nos mostra, ainda, que "a experiência da relação materna acolhedora e receptiva, também é responsảvel [pela] representação poderosa da morte [... ] como figura maternal, que acolhe, que dá conforto". Neste sentido, acreditamos que a forma como o profissional de enfermagem, relacionar-se-á com seu paciente estará intimamente associada com a sua maneira pessoal de representaçăo da morte e com suas marcas mais primitivas da vivència de ausência. 


\section{DIFICULDADES DIANTE DO TEMAMORTE}

Com relação à reação dos profissionais quando o paciente questiona sobre sua morte iminente, Mariana e Rosa disseram nunca terem sido questionadas sobre este tema pelos doentes. Esta resposta nos faz perguntar se de fato isto nunca aconteceu ou se ouvir o "outro" (paciente) falar de sua morte representa momento de intensa angústia e impotência para o profissional, que esta (angústia) o impede de escutar seu paciente.

Quatro profissionais disseram "contradizer" a fala do paciente. Parece ser uma tentativa de confortar e fazer o paciente acreditar que não vai morrer. Neste sentido o mecanismo de negação serve para confortar a si próprio da única certeza que temos na vida: a nossa própria finitude:

Há paciente que fala: não adianta fazer isto não, que eu vou morrer. Você procura dizer que não! É claro se você está no hospital, tá sendo cuidado, tá sendo medicado. A espera é melhorar e devolver a saúde para o paciente. Então que morrer que nada! Imagina! ... Eu vou fazer isso para você melhorar! Diz que a morte não é tão feia. Então tem que passar tranqüilidade para o paciente, se ele está internado, tá sendo medicado, é para melhorar, mesmo sabendo que essa verdade pode não servir para aquele paciente (Ana).

Teve um que falou "agora mesmo que eu vou morrer" e eu falei que não! que ele tem que tentar viver, näo pode deixar isso acontecer (Rita).

Eu nunca deixo eles pensar assim ... que eles vão morrer. Eu sempre procuro falar: não! Você vai ficar bom, a gente está cuidando, você tá tomando remédio, você está aqui. Se estivesse em casa poderia piorar, mas nunca falei: - se você morrer vai ser bom. Nunca falei isso para eles! (Carla).

A maioria tem medo e você tenta trabalhar ... colocar, dependendo ... o quê é e o que não é. Nunca dizer que ele vai morrer realmente. Os pacientes terminais perguntam: - "eu não vou sobreviver?" Você diz sempre tanto para a familia como para o paciente, que o estado é muito grave e não vai dizendo: - Olha ele vai morrer (Maria).

Estas falas vêem ao encontro das falácias existentes no hospital, já citadas anteriormente, e entre elas destacamos: há uma impossibilidade de aceitaçăo e preparação para a morte mesmo quando o paciente demonstra interesse e, o paciente não quer saber de sua morte. Percebemos, assim, que para o paciente torna-se dificil falar do morrer pois, não encontra, muitas vezes, alguém para ouvi-lo. Kübler-Ross (apud Boemer, Rossi; Nastari 1999,p.9) abordando sobre este tema afirma que "as evasivas săo tão claras, os conspiradores (...) tão inseguros que o aciente em geral sabe que vai morrer e também conspira para esconder dos outros o seu sentimento"

No entanto nossa experiência, no atendimento ao paciente fora de possibilidade terapêutica, nos mostrou que quando um paciente fala sobre a possibilidade de sua morte é porque está vivendo uma grande angústia frente as perdas que vem acontecendo; frente a impotência e o que eles mais desejam neste momento é poder dizer o quanto está sendo dificil.

Outros três entrevistados disseram abordar a questăo com o paciente sendo que, Joana e Vinicius se referem a aspectos "positivos" da vida do paciente:

Sei lá! Essas coisas vem na cabeça da gente na hora. De uma maneira geral quando os pacientes falam pra gente, eu vou morrer? ... a gente procura dizer pra ele: olha, você tá sofrendo, você precisa descansar, você já viveu tudo que tinha que viver ... fez coisas boas! Procura sempre entrar nesse lado (Joana).

Eu procuro mostrar a visão de Jesus, que o Reino de Deus é um Reino que não se iguala a nenhum, então eu procuro dizer que entrar no céu é o prêmio que a gente vai receber pelo bem que a gente fez aqui na terra (Vinicius).

Observamos, no entanto, que apenas Malu parece ser capaz de perceber a necessidade da elaboração do luto por parte do paciente e ajudá-lo neste momento: 
...muitas vezes [o paciente] questiona sobre o estado dele. Muitas vezes o paciente coloca que sabe que vai morrer, que está só esperando, que não tem mais o que fazer ... Sabe que a doença não tem cura. Então, como eu lidei muitos anos com pacientes assim, alguns anos atrás, eu tinha dificuldade em conversar com eles, em ouvir deles: - "sei que vou morrere não tem jeito". Ai eu sempre dizia: - não! não é assim, năo é por ai, olha, na vida tem que ter esperança. Agora, hoje, eu já consigo conversar melhor com o paciente, já consigo deixar ele elaborar o luto dele... Então ele acha que vai morrer, quer que chame a família. Ás vezes o paciente pede: - "olha eu gostaria de deixar algumas coisas resolvidas", então isso a gente já consegue melhor e muitos pacientes que eu lidei, são pacientes com câncer; então eles estão muito mal, e tem uma melhora, e nessa melhora às vezes é que o paciente pede para chamar alguém de casa, para dar uma olhadinha na filha (...) entäo são coisas que eu consigo ser cúmplice do paciente já (Malu).

Apesar das falas destes três profissionais mostrarem um movimento em favor da elaboração/preparação da morte para o paciente, consideramos que a atitude de Joana e Vinicius são discursos encobridores pois, dizer ao paciente que irá receber o Reino de Deus pelo que fez ou "que já viveu tudo o que tinha que viver e precisa descansar", pode colocar o paciente frente a mais ansiedade quando ele próprio considerar que fez coisas más ou não viveu tudo o que tinha para viver. Este discurso parece mostrar mais uma defesa dos profissionais, uma tentativa de "encerrarem" o assunto colocando apenas seu ponto de vista. Nossa experiência têm revelado que o paciente que elabora/aceita a morte pôde durante o processo de doença/ hospitalização integrar suas vivências.

\section{CONCLUSÄO}

No decorrer deste trabalho percebemos que as dificuldades pessoais dos profissionais que atuam no hospital podem interferir na dinâmica e no trabalho realizado junto ao paciente. $O$ profissional de enfermagem é o que, em geral, passa mais horas no contato direto com o paciente e portanto, vivenciam de maneira muito próxima as alegrias e tristezas de seus pacientes e familiares. A relação desse profissional com a morte é uma relação de angústia, visto que esta está associada a uma experiência de temor interiorizado. Este temor em hospital é a possibilidade de morte. Esta possibilidade vem se confrontar, no dia-a-dia do equipe de enfermagem, com a fantasia onipotente de imortalidade.

Para lidar com a angústia, todo individuo utiliza de mecanismos de defesa. Ao se utilizarem destes mecanismos para lidarem com a morte e o morrer, os profissionais de enfermagem podem deixar de perceber as limitaçōes e angústias do paciente e dessa forma deixar de ajudálo, não proporcionando a estes um dos cuidados que thes são conferidos, a assistência emocional. No entanto, verificamos que, para conseguir desenvolver seu trabalho, faz-se necessária a minimização de suas angústias e medos, o que torna menos dolorosa sua aproximação e separaçăo do paciente fora de possibilidade terapêutica. Podemos então afirmar que, em parte, os mecanismos de defesa protegem o profissional de enfermagem de vivenciar as perdas e tristezas às quais ele está sujeito dentro do hospital. Como afirma Kovács(1991,p. 79) ["a grande dádiva da negação e da repressão é permitir que se viva num mundo de fantasia onde, aparentemente, existe a ilusão da imortalidade. Se o medo da morte estivesse constantemente presente, não se conseguiria realizar nada".

No entanto, o que questionamos aqui não é a da utilização de defesas contra a angústia de morte, mas sim a cristalização das relações estruturadas em torno da morte, que torna, o hospital, um ambiente de trabalho árduo e dificil de suportar. Como bem os lembra Kovács $(1992$, p.3) "as defesas ao mesmo tempo que nos protegem do medo da morte, podem nos restringir". 
Desta forma, acreditar nas falácias discutidas por Guedes e Torres(1984), é um impedimento para que os equipe de enfermagem vivam plenamente a sua dor diante dos sofrimentos diários, ou seja, que faz com que o equipe de enfermagem mascare seus sentimentos "fingindo não sentir a dor que deveras sente". Assim, os sentimentos têm que ser "escondidos" e "disfarçados", como nos disse Maria, pois se o enfermeiro se colocar no lugar do outro (o paciente), pressupõe-se que este deveria viver seus sentimentos e afetividade, como está sendo vivido pelo paciente. Porém, como isto se torna insuportável para quem trabalha num lugar como um hospital, este profissional vive uma "mentira", não que seja "tornar-se" frio e calculista mas para "não se deixar cair". Como percebemos, todos os mecanismos envolvidos servem para a manutenção deste papel (frio e calculista), distanciando a afetividade, através de substituiçōes (por outros pacientes), inventando-se desculpas (racionalizando).

Neste trabalho, constatamos, que no hospital "O ideal é que [se] morra sem se dar conta de sua morte" (Maranhão, 1992,p.12), pois através das falas da equipe de enfermagem, estes tentam fazer com que os pacientes não percebam que "seu fim se aproxima" e, mais que isto, a própria equipe de enfermagem nega a si que o fim de seu paciente se aproxima, deixando assim de ter que deparar com sua impotência e tristeza e a possibilidade de uma melhor elaboração do luto.

As reações dos profissionais diante dos pacientes que morrem subitamente vem ao encontro do relatado por Costa (apud Cheida e Christófolli, 1984) em que estes se mobilizam desveladamente. Para os profissionais, esta morte é mais dificil de ser elaborada pois, a "sensação" é de que poderiam ter feito mais alguma coisa. Por isso, o paciente que morre aos poucos, dá a oportunidade ao enfermeiro de vivenciar esta perda como se ele tivesse feito o possivel pelo paciente.

Os relatos nos mostraram que os profissionais de enfermagem vivem com uma grande contradição diante de seu trabalho, entre o que Ihes foi ensinado e a realidade. O hospital é um lugar exclusivamente de cura, porém sabemos que houve um deslocamento do lugar da morte para o hospital (Maranhão, 1992). Sendo assim, parece haver um paradoxo entre o que o hospital é e o que querem que seja. Desta forma, podemos afirmar que há um cisão estabelecida (conflito) e que é causadora de angústia. Se a possibilidade de morte năo é permitida, como pode o profissional de enfermagem não se sentir perdedor ou impotente diante de um acontecimento que ele não consegue driblar na sua prática constante? Que tenhamos o cuidado de não nos equivocarmos com a necessidade de se abrir um "espaço para o morrer" na instituiçăo hospitalar, onde o paciente possa morrer com dignidade com a desistência de salvar vidas, pois é graças à esta lu ta pela vida que houve um grande avanço da medicina e a cura de muitos doentes.

Atualmente as grandes empresas, dentro da área de recursos humanos, procuram, oferecer melhores condições físicas e psicológicas de trabalho para seus funcionários, visando assim atingir um alto nivel de produtividade e de qualidade nos serviços prestados. Transportando essa idéia para a instituiçăo hospitalar, năo poderiamos deixar de incluir nessas melhores condiçöes psicológicas de trabalho, um apoio emocional aos profissionais que atuam no hospital. Principalmente o profissional de enfermagem que é o que permanece constantemente em contato com o doente e com situações estressantes. Em geral quando falamos em uma humanização da morte e do morrer, atentamos para a necessidade de um apoio emocional ao paciente. No entanto, nos esquecemos de que para que este apoio seja possivel é imprescindivel uma equipe de profissionais de saúde bem integrada emocionalmente com as questōes relacionadas ao seu cotidiano.

Dessa forma, acreditamos que é importante e de grande resultado oferecer ao profissional de enfermagem preparo emocional para seu trabalho pois, somente assim, estes poderão oferecer ao paciente não apenas os cuidados técnicos mas, também, um cuidado emocional quando este paciente solicitar sua presença para simplesmente dividir seus medos, esperanças ou que 
segure suas mãos quando estiver morrendo.

Acreditamos que uma mudança nas atitudes para com os pacientes fora de possibilidade terapêutica é necessária, e para que esta ocorra, uma mudança frente a morte e o morrer também se faz necessária e, como escreve Cassorla (1991,p.20), se permitirmos que a negaçāo da morte nos faça perder a capacidade de indignaçăo frente as mortes que acontecem dentro e fora do hospital, nas guerras, "em nossas ruas, em nossas desigualdades sociais, em nosso pais", estaremos matando, deixando morrer ou anestesiando partes de nossa condição humana.

Neste estudo, pudemos constatar que o psicólogo que irá intervir no trabalho junto á enfermagem, além de conhecer a dinâmica e o funcionamento desta equipe deve proporcionar um espaço terapêutico, para que as questões discutidas, possam ser trabalhadas de forma que propicie a estes profissionais um aprimoramento na relação com o paciente fora de possibilidade terapêutica. Desta forma, a expressão de sua dor diante da morte poderá ser ouvida e acolhida e permitirá a si mesmo e ao paciente vivenciar a dor, resultando numa morte mais digna para o paciente. No entanto, para que as intervenções psicológicas sejam satisfatórias, é necessário que o psicólogo esteja integrado a equipe multidisciplinar.

Sugerimos, assim, que o espaço terapêutico, no hospital, com profissionais de saúde, possa ser viabilizado através de grupos de reflexão, nas quais os profissionais possam expressar suas angústias, medos, impotências, etc. As intervençōes podem ser feitas através de clarificaçőes, pontuaçőes, questionamentos e interpretaçōes. Uma sensibilização para o trabalho é fundamental pois, a ideologia que impera é a de que não há espaço para se falar/viver os sentimentos no hospital. Técnicas de dinâmicas grupais e desenhos podem ser utilizadas como facilitadores da expressão dos conteúdos internos.

Gostariamos de ressaltar que o suporte dado pelo psicólogo clinico à equipe não se faz apenas nos grupos de reflexão mas no dia a dia da enfermaria, na trama vivida entre as vidas que escolheram o "hospital e a dor como oficio"

ABSTRACT: Through this paper which self explanatory and description we attempted to understand the reaction and feelings of nurses facing patients who are out of therapeutic possibility. W conducted individual, semi guided interviews with nine nurses from a general hospital in Maringa-PR about their reactions and feelings regarding forthcoming death on a daily base can be an extremely painful experience, therefore, they normally use self defense mechanics such as denial and reasoning death in order to live with daily losses. As a result these professional nurses may fail to notice the limits and their anxiety thus preventing them from providing a good quality of work in assisting their patients. Based on this fact we would like to suggest a prearranged space at the hospital where these health professionals could meet to share, reflect upon and express their anxieties, their fears, their helplessness and pain in face of death, enabling them to be better prepared for their daily losses.

KEYWORDS: nursing, hospital, death, patient out of therapeutic possibilities.

RESUMEN: A través de este estudio, del tipo exploratorio descriptivo proponemos comprender las reacciones y sentimientos de los profesionales de enfermeria delante de los pacientes fuera de posibilidade terapêutica. Fueron realizadas entrevistas individuales, semiconducidas com nueve profesionales de enfermeria (seis auxiliares de enfermeria y tres enfermeras) de un hospital general de la ciudad de Maringá-PR. Comprobamos que, para estos profesionales, el hecho de estar en contacto con la muerte diariamente es extremadamente angustioso y, por lo tanto, utilizam de mecanismos de defensa tales como negacion, racionalizacion, para que convivan con las pérdidas rutinarias. Debido a este hecho, los profesionales de enfermeria pueden dejar de percibir las limitaciones y angustias del paciente, lo que podrá comprometer la calidad del trabajo asistencial. Basándose en los resultados, sugestionamos la creación de un espacio terapéutico en el hospital. con los profesionales de la salud, para que a través de grupos de reflexión, la expresión de las angustias, miedos, impotencia y dolor delante de la muerte y del morir pueda ser facilitada y compartida.

PALAVRAS LLAVE: enfermeria, hospital, muerte, los pacientes fuera de posibilidad terapéutica 


\section{REFERÊNCIAS BIBLIOGRÁFICAS}

ALVES, R. N. ; GODOY, S. A. F. Reflexōes sobre a morte e a AIDS na rotina de enfermagem. Psicologia em estudo, Maringá, v.2, n.3, p.79-91, 1997.

BOEMER, M.R.; ROSSI, L.R.G. ; NASTARI, R.R. A idéia da morte em unidade de terapia intensivaanálise de depoimentos. Revista Gaúcha de Enfermagem, v.10, n.2, p. 8-14, jul. 1989.

CASSORLA, R. M. S. (coord.) Da morte. Campinas, Papirus: 1991.

CHEIDA, M.L.C. ; CHRISTÓFOLLI, D.A.S. A equipe de enfermagem frente à problemática da assistência individualizada ao paciente terminal. Revista Brasileira de Enfermagem, Brasilia, v.37, n.3/4, p.165173, jul./dez. 1984.

DEWALD, P. Psicoterapia - uma abordagem dinâmica. Porto Alegre: Artes Médicas, 1984.

FERNANDES, M.F.P.; FUJIMORI, M. ; KOIZUME, M.S. Estudo sobre as intervenções de enfermagem frente ao paciente em morte eminente. Revista Brasileira de Enfermagem, Brasilia, v.37, n.2, p. $102-108,1984$.

FERRAZ, A.F.; CARVALHO, D.V.; COSTA, T.M.P.F.; CARVALHO, W.S. Assistência de enfermagem a pacientes em fase terminal. Revista Brasileira de Enfermagem, Brasilia, v.39, n.1, p.50-60, jan.l mar. 1986.

FERREIRA, N.M.L.A. Assistência emocional - dificuldades do enfermeiro. Revista Baiana de Enfermagem, Salvador, v.5, n.1, p.30-41, out. 1992.

GUEDES, W.G. ; TORRES, W.C. A negaçăo da morte e suas implicaçōes na instituiçāo hospitalar. Arquivos Brasileiros de Psicologia, Rio de Janeiro, v.36, n.4, p.102-111, out./dez. 1984.

JOFFE, H. "Eu não", "meu grupo nāo": representaçōes sociais transculturais da AIDS. In JOVCHELOVITCH; GUARESCHI. Textos em Representaçōes Sociais. Petrópolis:Vozes, 1995.

KOVẢCS, M. J. Pensando a morte e a formaçăo de profissionais de saúde. In:CASSORLA, R. M. S. (Coord.) Da morte. Campinas, Papirus, 1991.

KOVẢCS, M. J. Morte e desenvolvimento humano. Sāo Paulo: Casa do Psicólogo, 1992.

MARANHĀO, J.L.S. O que é Morte. São Paulo: Brasiliense, 1992.

MENZIES, I.E.P. O Funcionamento das organizações como sistemas sociais de defesa contra a ansiedade. Trad. Arakcy M. Rodrigues, Săo Paulo,1970. mimeo.

PIVA, J.P. \& CARVALHO,P.R.A. Consideraçōes éticas nos cuidados médicos do paciente terminal. Bioética, v.1, n.2, p.129-138, 1993.

ROCKENBACH, L.H. A Enfermagem e a Humanização do Paciente. Revista Brasileira de Enfermagem, Brasilia, v.38, n.1, p.49-54, jan./mar. 1985.

SPINDOLA, T. \& MACEDO, M.C.S. A morte no hospital e seu significado para os profissionais, Revista Brasileira de Enfermagem, Brasilia, v.47, n.2, p.108-117, abr./jun. 1994.

TORRES, W.C.; GUEDES, W. G.; TORRES, R.C. ; EBERT, T.H. Atitudes frente a morte: implicaçōes na formaçăo de equipe profissionais multidisciplinares. Arquivos Brasileiros de Psicologia, Rio de Janeiro, v.41, n.1, p.43-72, fev. 1989. 